\title{
SVN Isanem \\ Role of lipocalin 2 in intraventricular haemoglobin-induced brain injury
}

\author{
Hajime Shishido, Yasunori Toyota, Ya Hua, Richard F Keep, Guohua Xi
}

To cite: Shishido $\mathrm{H}$ Toyota $Y$, Hua $Y$, et al. Role of lipocalin 2 in intraventricular haemoglobininduced brain injury. Stroke and Vascular Neurology 2016:1:e000009.

doi:10.1136/svn-2016000009

Received 7 January 2016 Revised 12 April 2016 Accepted 14 April 2016 Published Online First 28 April 2016

\section{CrossMark}

Department of Neurosurgery, University of Michigan, Ann Arbor, Michigan, USA

Correspondence to Dr Guohua Xi; guohuaxi@umich.edu

\section{ABSTRACT}

Objective: Our recent studies have shown that blood components, including haemoglobin and iron, contribute to hydrocephalus development and brain injury after intraventricular haemorrhage (IVH). The current study investigated the role of lipocalin 2 (LCN2), a protein involved in iron handling, in the ventricular dilation and neuroinflammation caused by brain injury in a mouse model of IVH.

Design: Female wild-type (WT) C57BL/6 mice and LCN2-deficient $\left(\mathrm{LCN}^{-/-}\right)$mice had an intraventricular injection of haemoglobin, and control mice received an equivalent amount of saline. MRI was performed presurgery and postsurgery to measure ventricular volume and the brains were used for either immunohistochemistry or western blot.

Results: Ventricular dilation was observed in WT mice at $24 \mathrm{~h}$ after haemoglobin $(25 \mathrm{mg} / \mathrm{mL}, 20 \mu \mathrm{L})$ injection (12.5 \pm 2.4 vs $8.6 \pm 1.5 \mathrm{~mm}^{3}$ in the control, $p<0.01$ ). Western blotting showed that LCN2 was significantly upregulated in the periventricular area $(p<0.01)$. LCN2 was mainly expressed in astrocytes, whereas the LCN2 receptor was detected in astrocytes, microglia/ macrophages and neurons. Haemoglobin-induced ventricle dilation and glia activation were less in $\mathrm{LCN}^{-1-}$ mice $(\mathrm{p}<0.01)$. Injection of high-dose haemoglobin $(50 \mathrm{mg} / \mathrm{mL})$ resulted in lower mortality in $\mathrm{LCN}^{-l-}$ mice $(27 \%$ vs $86 \%$ in $\mathrm{WT} ; \mathrm{p}<0.05)$.

Conclusions: Intraventricular haemoglobin caused LCN2 upregulation and ventricular dilation. Haemoglobin resulted in lower mortality and less ventricular dilation in $\mathrm{LCN}^{-/-}$mice. These results suggest that LCN2 has a role in haemoglobin-induced brain injury and may be a therapeutic target for IVH.

\section{INTRODUCTION}

Acute hydrocephalus is a common complication following haemorrhagic stroke. Almost $50 \%$ of intracerebral haemorrhages cause the development of hydrocephalus, ${ }^{1}$ and the incidence of acute hydrocephalus within 3 days of subarachnoid haemorrhage ranges from $20 \%$ to $63 \% .^{2}{ }^{3}$ It has been reported that the presence of intraventricular haemorrhage (IVH) is the major factor related to hydrocephalus. ${ }^{4}$ Our previous study demonstrated that IVH causes lateral ventricle dilation and that iron plays a role in
IVH-induced brain injury and ventricular enlargement in rats. ${ }^{5}$

Lipocalin 2 (LCN2) is a siderophorebinding protein that has a role in endogenous iron chelation. It has a bacteriostatic effect by competing with bacteria for iron loading. ${ }^{6}$ In the central nervous system, LCN2 is an acute phase protein ${ }^{7}$ and is expressed following spinal traumatic injury, ischaemic stroke, ${ }^{9}$ intracerebral haemorrhage $^{1011}$ and neuroinflammation. ${ }^{12}$ Diverse functions of LCN2 have been reported. Thus, it has been associated with neuronal cell death, ${ }^{13}$ reactive astrocytosis ${ }^{14}$ and activated microglia. ${ }^{15}$ However, little is known about the role of LCN2 in IVH-induced hydrocephalus.

The present study addressed the hypothesis that LCN2 may have a potential role in acute ventricular dilation after IVH in mice after haemoglobin injection.

\section{MATERIALS AND METHODS}

Animal preparation and haemoglobin injection into the ventricle

Animal-use protocols were approved by the University of Michigan Committee on the Use and Care of Animals. Animals were housed under standard 12:12 light-dark conditions and allowed free water and food. A total of 31 adult female wild-type (WT) C57BL/6 mice (19-24 g; Charles River Laboratories) and 21 adult female LCN2-deficient $\left(\mathrm{LCN}^{-/-}\right.$) mice (19-27 g; University of Michigan Breeding Core, gift from Dr Xiaoli Chen, University of Minnesota) were used in this study. Animals were anaesthetised with ketamine $(90 \mathrm{mg} / \mathrm{kg})$ and xylazine $(5 \mathrm{mg} / \mathrm{kg})$ intraperitoneally and core body temperature was kept at $37.0^{\circ} \mathrm{C}$ with a controlled heating pad. Mice were positioned in a stereotaxic frame (Kopf Instruments, Tujunga, California, USA). A midline scalp incision was performed to expose the central areas of the skull between the coronal and lambdoid sutures. A cranial burr hole was drilled and a 26-gauge needle inserted stereotaxically into 
the right lateral ventricle (coordinates: $0.5 \mathrm{~mm}$ posterior, $1.1 \mathrm{~mm}$ lateral to the bregma and $2.6 \mathrm{~mm}$ ventral). Either haemoglobin or saline was injected over $5 \mathrm{~min}$ using a microinfusion pump (World Precision Instruments, Sarasota, Florida, USA). After injection, the needle was removed, the burr hole filled with bone wax and the skin incision was closed with sutures.

\section{Experimental groups}

This study included three parts. First, WT mice received a $20 \mu \mathrm{L}$ injection of saline only $(n=6)$ or haemoglobin ( $\mathrm{n}=8$, bovine haemoglobin; $25 \mathrm{mg} / \mathrm{mL}$, ICN Biomedical Inc, Aurora, Ohio, USA) in saline into the right lateral ventricle. MRI was performed $24 \mathrm{~h}$ later and the mice were then euthanised for immunohistochemistry and western blot analysis. Second, WT and $\mathrm{LCN}^{-/-}$mice had an intraventricular injection of haemoglobin $(25 \mathrm{mg} / \mathrm{mL}$ in $20 \mu \mathrm{L}$ saline) or saline only $(\mathrm{n}=5$ for each). They underwent MRI presurgery and postsurgery at $24 \mathrm{~h}$. Mice were then euthanised for immunohistochemistry. Third, WT $(n=7)$ and $\mathrm{LCN}^{-/-}$mice $(\mathrm{n}=11)$ received an intraventricular injection of a high dose of haemoglobin $(50 \mathrm{mg} / \mathrm{mL}, 20 \mu \mathrm{L})$. The mortality rate was determined at $24 \mathrm{~h}$.

\section{MRI for ventricular volume measurement}

MRI was performed in a 7.0-T Varian MR scanner (Varian) with acquisition of T2 fast spin-echo sequences, using a field of view of $20 \times 20 \mathrm{~mm}$, matrix of $256 \times 256 \mathrm{~mm}$ and 25 coronal slices $(0.5 \mathrm{~mm}$ thick $)$. Mice were anaesthetised with $1.5 \%$ isoflurane throughout the MRI examination. Ventricular volume was measured as described previously. ${ }^{5}$ Briefly, ventricles from the frontal horn of the lateral ventricles to the foramen of Luschka were outlined and measured. Ventricular volume was calculated by totalling the ventricular areas over all slices and multiplying by section thickness. All image analysis was performed using ImageJ software, by an observer blinded to the experimental group. For the comparison between genotypes, ventricular volumes were measured before and after haemoglobin and saline injection, and ventricular dilation was determined as a per cent increase compared with presurgical values.

\section{Immunohistochemistry}

Brains were postfixed in $4 \%$ formaldehyde and immersed in $30 \%$ sucrose in $0.1 \mathrm{M}$ cold phosphatebuffered saline ( $\mathrm{pH}$ 7.4) for $2-3$ days at $4^{\circ} \mathrm{C}$. They were then embedded and sliced into $18 \mu \mathrm{m}$-thick coronal sections on a cryostat. Immunohistochemical staining was performed using the avidin-biotin complex technique. Sections were incubated in either 1:10 rabbit or goat serum (Vector Laboratories) for $30 \mathrm{~min}$ and then incubated overnight with primary antibody. The antibodies were: polyclonal goat anti-LCN2 (1:200 dilution, B\&D System), polyclonal rabbit antiglial fibrillary acidic protein (GFAP; 1:1000 dilution, Millipore) and polyclonal goat anti-Iba-1 (1:400 dilution, Abcam). The secondary antibodies were rabbit antigoat IgG (Bio-Rad; 1:1000) or goat antirabbit IgG (Bio-Rad; 1:1000). Negative immunohistochemical control procedures included omission of the primary antibody.

\section{Immunofluorescent double labelling}

For immunofluorescent double labelling, sections were incubated with $15 \%$ normal donkey serum at room temperature for $30 \mathrm{~min}$ and then incubated overnight at $4^{\circ} \mathrm{C}$ with primary antibodies. After washing, sections were incubated with secondary antibodies for $2 \mathrm{~h}$. The primary antibodies were polyclonal goat anti-LCN2 (1:200 dilution, R\&D system), polyclonal rabbit anti-SLC22A17 (marker for LCN2 receptor, 1:50 dilution, Abcam), polyclonal mouse anti-GFAP (1:400 dilution, Millipore), monoclonal mouse anti-neuronal nuclei (NeuN; 1:100 dilution, Millipore) and polyclonal goat anti-Iba1 (1:500 dilution, Abcam) or rabbit anti-Iba-1 (1:500 dilution, Wako). The secondary antibodies were donkey antigoat $\operatorname{IgG}(\mathrm{H}+\mathrm{L})$ Alexa Fluor 594 (1:500 dilution, Invitrogen), donkey antirabbit $\operatorname{IgG}(\mathrm{H}+\mathrm{L})$ Alexa Fluor 594 (1:500 dilution, Invitrogen), donkey antimouse $\operatorname{IgG}(\mathrm{H}+\mathrm{L})$ Alexa Fluor 488 (1:500 dilution, Invitrogen), donkey antirabbit $\operatorname{IgG}(\mathrm{H}+\mathrm{L})$ Alexa Fluor 488 (1:500 dilution, Invitrogen) and donkey antigoat $\operatorname{IgG}(\mathrm{H}+\mathrm{L})$ Alexa Fluor 488 (1:500 dilution, Invitrogen). The double labelling was analysed using a fluorescence microscope.

\section{Western blot analysis}

A $3 \mathrm{~mm}$ thick coronal brain slice was cut $3 \mathrm{~mm}$ from the frontal pole. The ipsilateral cortex and periventricular area including white matter were sampled. Samples were sonicated in western blot sample buffer. Protein concentrations were determined by Bio-Rad protein assay kit and $10 \mu \mathrm{g}$ protein samples separated by sodium dodecyl sulfate-polyacrylamide gel electrophoresis, and transferred to a Hybond-C pure nitrocellulose membrane (Amersham). Membranes were probed with primary antibody: polyclonal goat anti-LCN2 (1:200 dilution, R\&D system). The secondary antibody was rabbit antigoat IgG (1:1000 dilution, Bio-Rad). Image analysis was performed using Image J software by a blinded observer.

\section{Cell counting}

The numbers of GFAP and Iba-1 immunopositive cells were measured on high-power images $(\times 40$ magnification) taken in the periventricular area by a digital camera, using sections $0.5 \mathrm{~mm}$ anterior from the bregma. The numbers of activated astrocytes and microglia were counted by a blinded observer and statistically analysed as previously described, ${ }^{9}{ }^{16}$ using the National Institutes of Health (NIH) imageJ programme. Three regions of interest were examined per section and all measurements counted on three sections, and the mean values were used. 


\section{Statistical analysis}

Values are presented as the means \pm SD. Statistical differences among groups were analysed using Student's t test or one-way analysis of variance with a Tukey's all pair's comparison. Statistical significance was set at $\mathrm{p}<0.05$.

\section{RESULTS}

\section{Development of ventricular dilation}

No mice died after saline or $25 \mathrm{mg} / \mathrm{mL}$ haemoglobin injection. Ventricular volumes $24 \mathrm{~h}$ after haemoglobin injection $\left(12.5 \pm 2.4 \mathrm{~mm}^{3} ; \mathrm{n}=8\right)$ were significantly larger than those in mice receiving saline injection (8.6 $\pm 1.5 \mathrm{~mm}^{3} ; \mathrm{n}=6 ; \mathrm{p}<0.01$, figure 1 ).

\section{Expression of LCN2 after haemoglobin injection}

Using immunohistochemistry, we found that periventricular and cortical LCN2 immunoreactivity was very weak in the saline injection group (figure 2A). In contrast, there was marked LCN2 expression of LCN2 in both areas $24 \mathrm{~h}$ after haemoglobin injection (figure $2 \mathrm{~B}$ ). By western blot, haemoglobin increased LCN2 protein

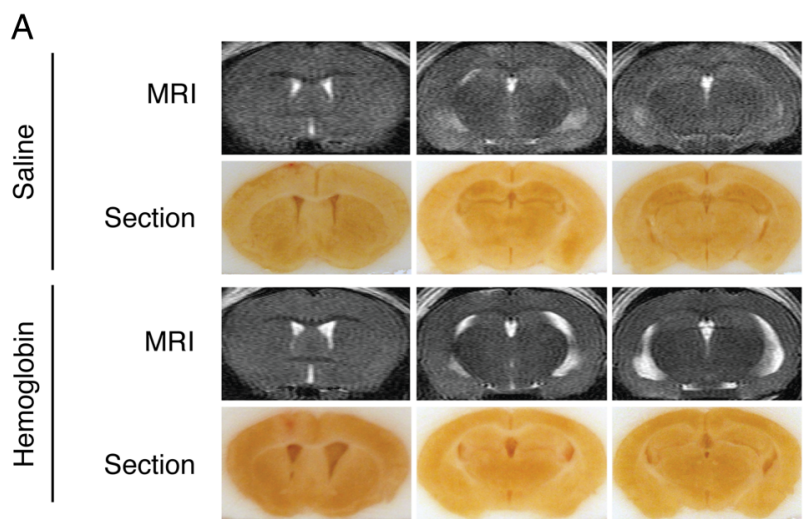

B

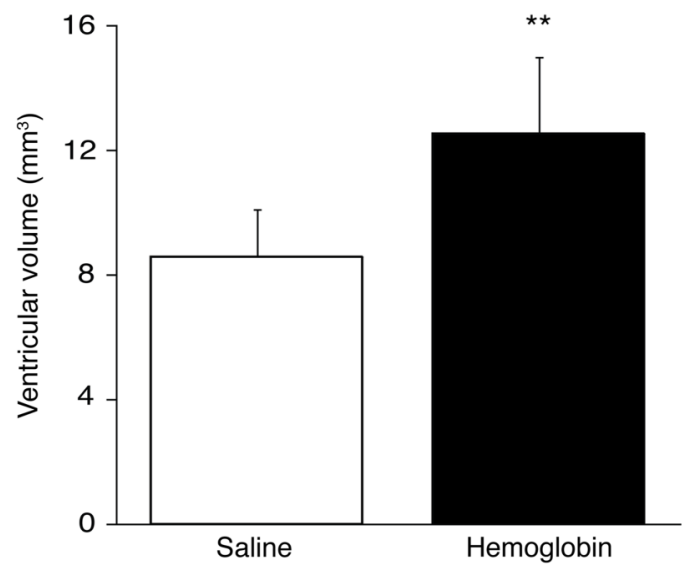

Figure 1 Intraventricular injection of haemoglobin caused ventricular dilation. T2-weighted MRI and frozen coronal brain sections (A) and the measurement of ventricular volume with T2-weighted MRI (B) from mice $24 \mathrm{~h}$ after injection of $20 \mu \mathrm{L}$ of saline or haemoglobin $(25 \mathrm{mg} / \mathrm{mL})$ into the right lateral ventricle. The data points represent means $\pm S D, n=6-8$, ${ }^{* *} \mathrm{p}<0.01$ versus saline group. levels $\sim 20$-fold compared with saline injection at $24 \mathrm{~h}$ in both the periventricular area $(26362 \pm 4165$ vs $2780 \pm 579$ pixels in the control, $\mathrm{n}=3-5, \mathrm{p}<0.01$, figure $2 \mathrm{C}$ ) and cortex (12 352 \pm 2812 vs $687 \pm 215$ pixels in the control, $\mathrm{n}=3-5, \mathrm{p}<0.01$, figure 2D).

\section{LCN2 was mainly expressed in astrocytes}

Double-labelling immunofluorescence was used to determine which cell types expressed LCN2 after haemoglobin injection. LCN2 immunoreactivity predominantly co-localised with GFAP-positive cells in the periventricular area. LCN2 immunoreactivity did not co-localise with Iba-1-positive cells and only a few LCN2-positive cells in the cortex were also NeuN positive (figure 3).

\section{LCN2 receptor was expressed in astrocytes, microglia and neurons}

Double-labelling immunofluorescence was also used to determine which cell types expressed the LCN2 receptor (SLC22A17) after haemoglobin injection. Co-expression of SLC22A17 immunoreactivity with GFAP-positive cells was observed in the periventricular area. Co-expression of SLC22A17 immunoreactivity and Iba-1-positive cells was also detected in the periventricular area and ependymal layer. Co-expression of SLC22A17 and NeuN immunoreactivity was observed in the cortex (figure 4).

\section{LCN2 and haemoglobin-induced ventricular dilation}

$\mathrm{WT}$ and $\mathrm{LCN}^{-/-}$mice each received an intraventricular injection of haemoglobin $(25 \mathrm{mg} / \mathrm{mL})$ or saline only $(\mathrm{n}=5$ for each). In the saline injection group, the increase in ventricular volume compared with preinjection MRI was not significantly different between WT and LCN2 $^{-/-}$mice $(10 \pm 5 \%$ vs $7 \pm 4 \%$, respectively, $\mathrm{n}=5$ for each, $\mathrm{p}>0.05)$. However, the increase in ventricular volume induced by haemoglobin $(25 \mathrm{mg} / \mathrm{mL})$ injection was significantly lower in LCN2 ${ }^{-/-}$mice $(7 \pm 8 \%$ vs 45 $\pm 19 \%$ in saline controls, $\mathrm{p}<0.01$, figure 5 ).

\section{Glial and microglial activation}

In the saline injection groups, the number of GFAP and Iba-1-positive cells in periventricular area was not significantly different between WT and $\mathrm{LCN}^{-/-}$mice ( $p>0.05$; figure 6$)$. At $24 \mathrm{~h}$ after haemoglobin injection, the numbers of both GFAP-positive cells and Iba-1-positive cells were significantly increased in the periventricular area of WT mice (figure 6). Those increases were significantly lower in $\mathrm{LCN}^{-/-}$mice $(\mathrm{p}<0.01$, figure 6$)$.

\section{Mortality after high-dose haemoglobin injection}

Intraventricular injection of a higher dose of haemoglobin $(50 \mathrm{mg} / \mathrm{mL}, 20 \mu \mathrm{L})$ resulted in high mortality in WT mice by $24 \mathrm{~h}(86 \%, 6 / 7)$. In contrast, there was much lower mortality in $\mathrm{LCN}^{-/-}$mice $(27 \%, 3 / 11$; $\mathrm{p}<0.05)$. 
A

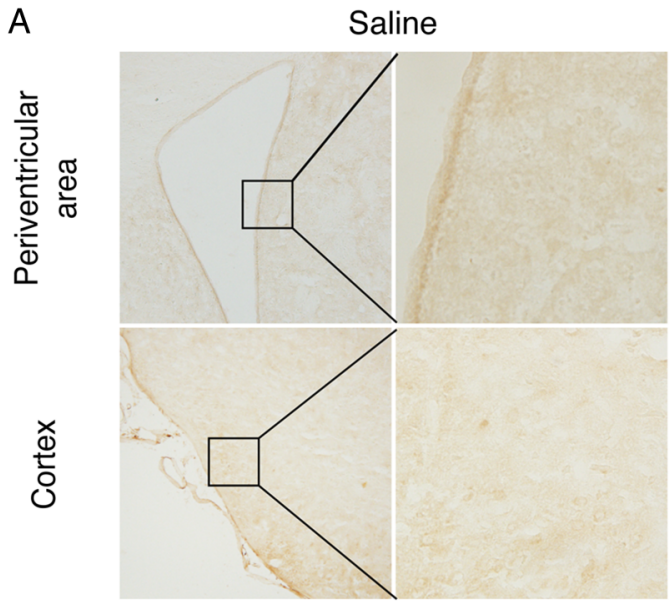

C
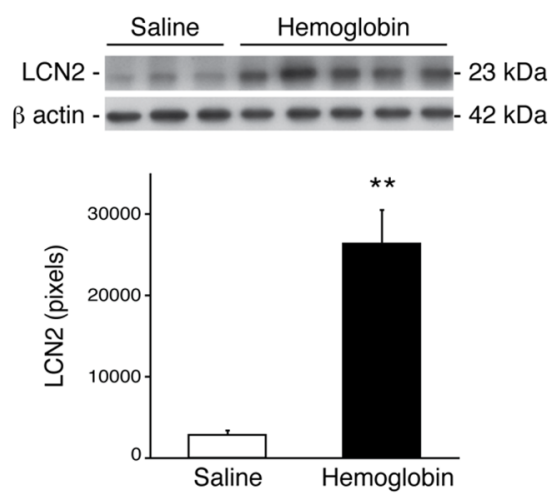

B

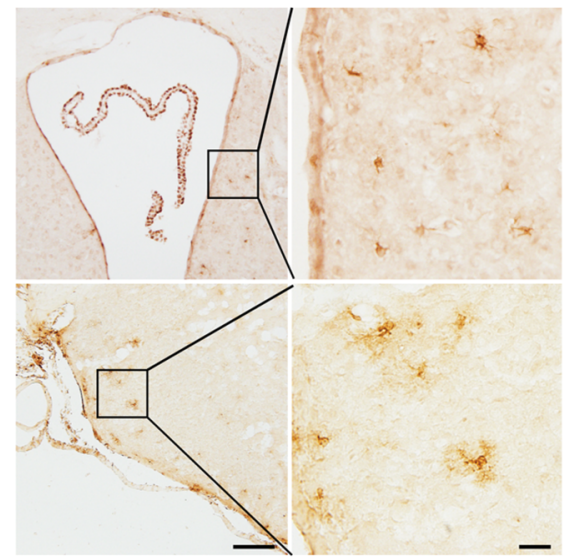

D Cortex
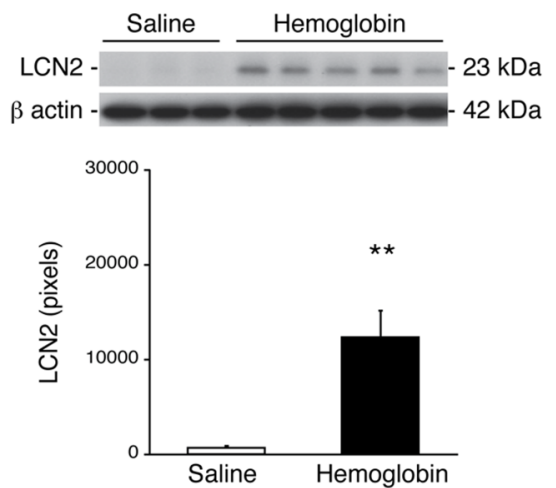

Figure 2 Lipocalin 2 (LCN2) protein was markedly upregulated in the brain $24 \mathrm{~h}$ after intraventricular haemoglobin injection compared with saline controls. Immunohistochemistry staining demonstrated that LCN2 immunoreactivity was expressed in the periventricular area and cortex $24 \mathrm{~h}$ after intraventricular haemoglobin injection (A) compared with saline controls (B). Boxes show areas examined at higher magnification in the higher power micrographs on the right (scale bars $=100$ and $20 \mu \mathrm{m}$ ). LCN2 protein levels were upregulated in the periventricular area (C) and cortex (D) $24 \mathrm{~h}$ after intraventricular haemoglobin injection, as shown by western blot. The data points represent means $\pm S D, n=3-5,{ }^{* *} p<0.01$ versus saline group.

\section{DISCUSSION}

The present study has several major findings: (1) intraventricular haemoglobin injection caused ventricular dilation and neuroinflammation in the periventricular area; (2) LCN2 expression was markedly increased in the periventricular area and cortex after haemoglobin injection; (3) $\mathrm{LCN}^{-/}$mice had less haemoglobininduced ventricular dilation with less glial activation and (4) in a high-dose haemoglobin injection model, there was lower mortality rate in $\mathrm{LCN}^{-/-}$mice compared with WT controls.

Posthaemorrhagic hydrocephalus is traditionally thought to involve: (1) arachnoid obstruction by blood components; (2) subarachnoid fibrosis and (3) ventricular wall damage. Consequently, impaired cerebrospinal fluid (CSF) flow, excess CSF production and lack of CSF reabsorption may result in the development of hydrocephalus. ${ }^{17}$ Normal ependymal cells are associated with the homoeostasis of CSF in the brain and ependymal dysfunction may result in the development of hydrocephalus. ${ }^{17}$ Other reports have indicated that development of ventriculomegaly is associated with a reaction of periventricular astrocytes. ${ }^{18}{ }^{19}$ However, the precise mechanisms of IVH-induced hydrocephalus are still not fully understood. Our previous studies have shown that intraventricular injection of autologous arterial blood, ${ }^{5}$ lysed red blood cells ${ }^{20}$ and haemoglobin ${ }^{21}$ result in marked ventricular enlargement in rats, and that iron accumulation is associated with IVH-induced hydrocephalus. ${ }^{5}$ In addition, iron is involved in LCN2 regulation with deferoxamine, an iron chelator, reducing LCN2 upregulation in a rat model of intracerebral haemorrhage. ${ }^{21}$ In the present study, we demonstrated that intraventricular haemoglobin injection induced acute ventricular dilation in the mouse, and that LCN2 is also upregulated in the periventricular area and cortex. LCN2 expression can be strongly enhanced by kainate,$^{12}$ lipopolysaccharide ${ }^{22}$ and iron. ${ }^{10}$ Haemoglobin consists of haem and globin. Haem is degraded into carbon monoxide, biliverdin and iron in the brain, 
Figure 3 Immunoreactivity for lipocalin 2 (LCN2), glial fibrillary acidic protein (GFAP), Iba-1 and neuronal nuclei (NeuN) $24 \mathrm{~h}$ after intraventricular haemoglobin injection. Immunofluorescent double labelling showed that LCN2-positive cells were mainly astrocytes. Scale bar $=50 \mu \mathrm{m}$.

Figure 4 Immunoreactivity for the lipocalin 2 (LCN2) receptor (SLC22A17), glial fibrillary acidic protein (GFAP), Iba-1 and neuronal nuclei (NeuN) $24 \mathrm{~h}$ after intraventricular haemoglobin injection. Co-localisation of the LCN2 receptor with GFAP, Iba-1 and NeuN by double labelling is shown. Scale bar $=50 \mu \mathrm{m}$.
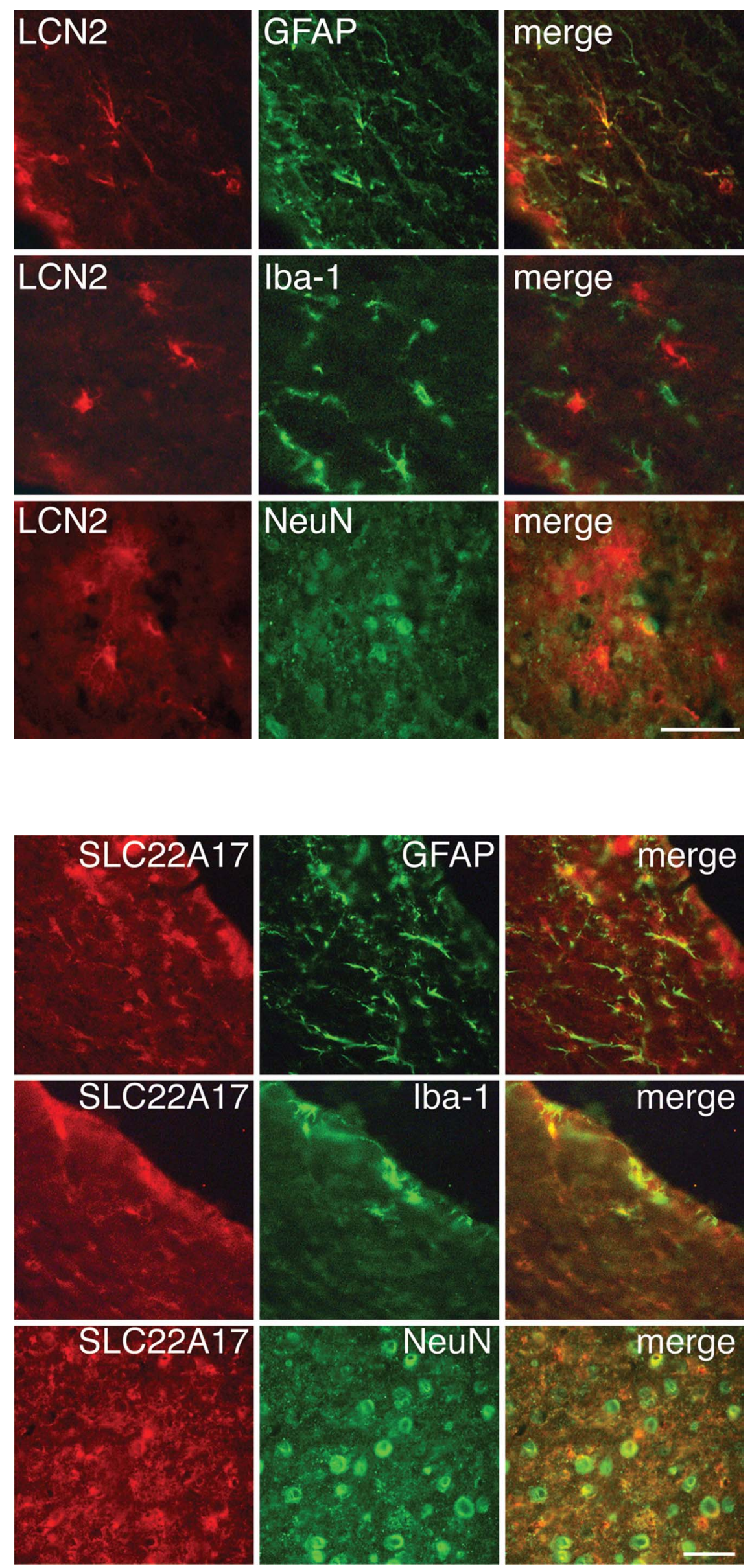


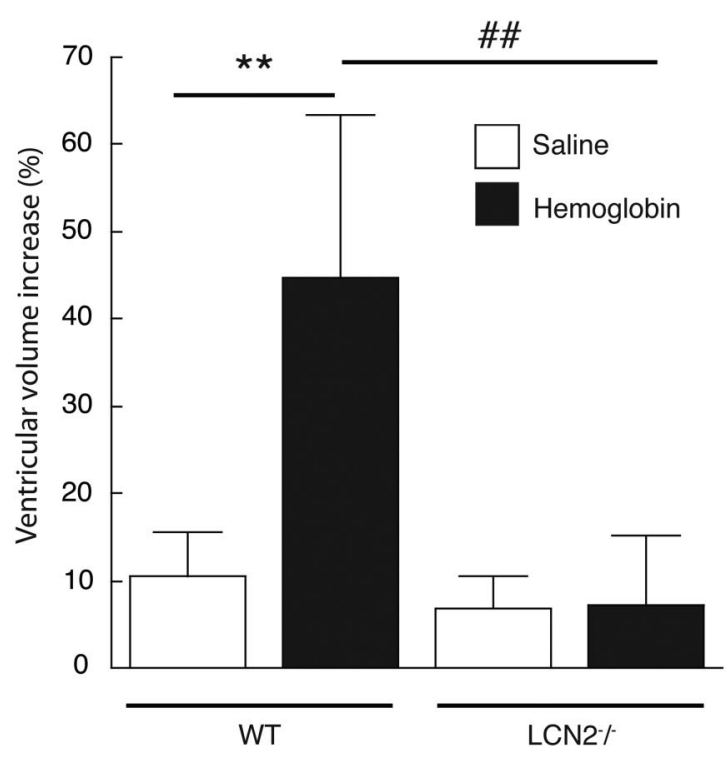

Figure 5 Ventricular volumes were measured before and after $(24 \mathrm{~h})$ the injection of haemoglobin $(25 \mathrm{mg} / \mathrm{mL})$ or saline into wild-type (WT) and in lipocalin 2-deficient (LCN2 ${ }^{-/}$) mice. Ventricular dilation was calculated as a per cent of presurgery values. Haemoglobin caused marked ventricular dilation in WT mice compared with saline controls, but not $\mathrm{LCN}^{-/-}$mice. The data represent means $\pm \mathrm{SD}, \mathrm{n}=5$ for each, ${ }^{* *} p<0.01$ versus WT saline group, ${ }^{\# \#} p<0.01$ versus $L C N 2^{-/-}$ haemoglobin group.

resulting in iron overload in the brain after haemorrhagic stroke. A previous study has suggested that LCN2 can bind to iron and deliver it to the cells through a process of endocytosis. ${ }^{23}$ Increasing evidence indicates that iron released from haem may contribute to acute hydrocephalus. ${ }^{21} 24$ These results suggest that LCN2 induced by haemoglobin may take part in the development of ventricular dilation by participating in iron overload.

We assessed which cell types express LCN2 and the LCN2 receptor after haemoglobin injection by immunofluorescent double labelling. We found that LCN2 was mainly expressed in astrocytes and that the LCN2 receptor was expressed in astrocytes, microglia and neurons. We hypothesise that after an IVH, the release of haemoglobin induces reactive astrocytes to secrete LCN2, which then influences neuronal and glia function via the LCN2 receptor.

The role of LCN2 in the central nervous system has not been well studied. The present study revealed that $\mathrm{LCN}^{-/-}$mice have less ventricle dilation, and lower numbers of activated astrocytes and amoeboid microglia after haemoglobin injection. Previous studies have found that LCN2 causes increased GFAP expression ${ }^{14}$ and promotes astrocyte and microglia activation. ${ }^{25}$ Another recent study indicated that LCN2 deficiency attenuates neuroinflammation by reducing glial and microglial activation in a systemic inflammation model. ${ }^{26}$

The present study found the intraventricular injection of a high dose of haemoglobin caused less mortality in $\mathrm{LCN}^{-1-}$ mice compared with WT mice. A previous study also demonstrated a lower mortality rate in $\mathrm{LCN}^{-/-}$mice than in WT mice in a brain ischaemia/ reperfusion model. ${ }^{9}$ In that study, $\mathrm{LCN}^{-/-}$mice also had reduced glial activation. The results suggest that LCN2 secreted by reactive astrocytes may act to promote neuroinflammation, resulting in the development of brain injury, acute ventricular dilation and mortality. Further studies should determine the pathways by which LCN2 taking participates in brain injury following IVH.
A

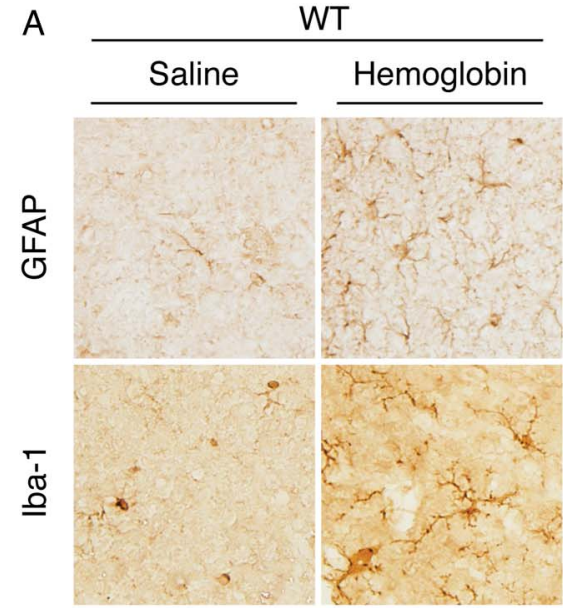

$\mathrm{LCN}^{-1-}$

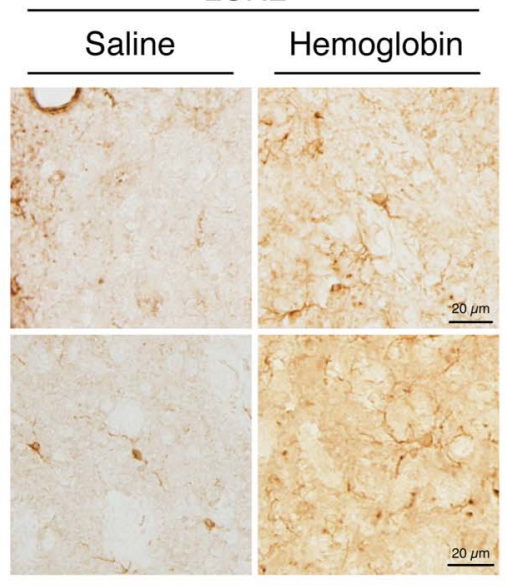

B

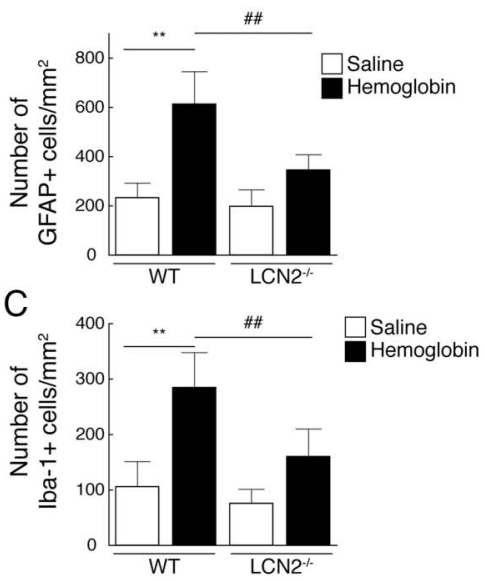

Figure 6 In wild-type (WT) mice, intraventricular injection of haemoglobin $(25 \mathrm{mg} / \mathrm{mL})$ resulted in periventricular activation of astrocytes (glial fibrillary acidic protein (GFAP) staining) and microglia (amoeboid lba-1 staining) at $24 \mathrm{~h}$ compared with saline-injected controls (A). The activation by haemoglobin was attenuated in lipocalin 2-deficient $\left(\mathrm{LCN2}^{-l-}\right)$ mice $(\mathrm{A})$. The numbers of periventricular cells expressing GFAP (B) and Iba-1 (C) were counted in the WT and LCN2 ${ }^{-/}$mice. The data points represent the mean $\pm S D$, scale bar $=50 \mu \mathrm{m}, \mathrm{n}=5$ per group; ${ }^{* *} \mathrm{p}<0.01$ versus WT saline group, ${ }^{\# \#} \mathrm{p}<0.01$ versus $\mathrm{LCN} 2^{-/-}$ haemoglobin group. 


\section{CONCLUSION}

The present study demonstrates that intraventricular haemoglobin injection causes marked periventricular upregulation of LCN2 and acute ventricular dilation, and can cause death in mice. The adverse effects of haemoglobin were ameliorated in $\mathrm{LCN}^{-/-}$mice, suggesting that LCN2 may have a role in the development of hydrocephalus and brain injury after IVH.

Funding This study was supported by grants NS-073595, NS-079157, NS-084049, NS-091545 and NS-090925, from the National Institutes of Health (NIH)

Disclaimer The content is solely the responsibility of the authors and does not necessarily represent the official views of the NIH.

Competing interests None declared.

Provenance and peer review Commissioned; externally peer reviewed.

Data sharing statement No additional data are available.

Open Access This is an Open Access article distributed in accordance with the Creative Commons Attribution Non Commercial (CC BY-NC 4.0) license, which permits others to distribute, remix, adapt, build upon this work noncommercially, and license their derivative works on different terms, provided the original work is properly cited and the use is non-commercial. See: http:// creativecommons.org/licenses/by-nc/4.0/

\section{REFERENCES}

1. Diringer MN, Edwards DF, Zazulia AR. Hydrocephalus: a previously unrecognized predictor of poor outcome from supratentorial intracerebral hemorrhage. Stroke 1998;29:1352-7.

2. Black PM. Hydrocephalus and vasospasm after subarachnoid hemorrhage from ruptured intracranial aneurysms. Neurosurgery 1986;18:12-16.

3. Hasan D, Vermeulen M, Wijdicks EF, et al. Management problems in acute hydrocephalus after subarachnoid hemorrhage. Stroke 1989;20:747-53.

4. Dorai Z, Hynan LS, Kopitnik TA, et al. Factors related to hydrocephalus after aneurysmal subarachnoid hemorrhage. Neurosurgery 2003;52:763-9; discussion 769-71.

5. Chen Z, Gao C, Hua Y, et al. Role of iron in brain injury after intraventricular hemorrhage. Stroke 2011:42:465-70.

6. Neilands JB. Siderophores: structure and function of microbial iron transport compounds. J Biol Chem 1995;270:26723-6.

7. Marques F, Rodrigues AJ, Sousa JC, et al. Lipocalin 2 is a choroid plexus acute-phase protein. J Cereb Blood Flow Metab 2008;28:450-5.
8. Rathore KI, Berard JL, Redensek A, et al. Lipocalin 2 plays an immunomodulatory role and has detrimental effects after spinal cord injury. J Neurosci 2011;31:13412-19.

9. Jin $\mathrm{M}, \mathrm{Kim} \mathrm{JH}$, Jang $\mathrm{E}$, et al. Lipocalin-2 deficiency attenuates neuroinflammation and brain injury after transient middle cerebral artery occlusion in mice. $J$ Cereb Blood Flow Metab 2014;34:1306-14.

10. Dong M, Xi G, Keep RF, et al. Role of iron in brain lipocalin 2 upregulation after intracerebral hemorrhage in rats. Brain Res 2013;1505:86-92.

11. Ni W, Zheng M, Xi G, et al. Role of lipocalin-2 in brain injury after intracerebral hemorrhage. J Cereb Blood Flow Metab 2015;35:1454-61.

12. Chia WJ, Dawe GS, Ong WY. Expression and localization of the iron-siderophore binding protein lipocalin 2 in the normal rat brain and after kainate-induced excitotoxicity. Neurochem Int 2011;59:591-9.

13. Bi F, Huang $\mathrm{C}$, Tong $\mathrm{J}$, et al. Reactive astrocytes secrete Icn2 to promote neuron death. Proc Natl Acad Sci USA 2013;110:4069-74.

14. Lee S, Park JY, Lee WH, et al. Lipocalin-2 is an autocrine mediator of reactive astrocytosis. $J$ Neurosci 2009;29:234-49.

15. Lee S, Lee J, Kim S, et al. A dual role of lipocalin 2 in the apoptosis and deramification of activated microglia. $\mathrm{J}$ Immunol 2007;179:3231-41.

16. Kalla R, Bohatschek $\mathrm{M}$, Kloss $\mathrm{CU}$, et al. Loss of microglial ramification in microglia-astrocyte cocultures: Involvement of adenylate cyclase, calcium, phosphatase, and gi-protein systems. Glia 2003;41:50-63.

17. Banizs B, Pike MM, Millican CL, et al. Dysfunctional cilia lead to altered ependyma and choroid plexus function, and result in the formation of hydrocephalus. Development 2005;132:5329-39.

18. Shook BA, Lennington JB, Acabchuk RL, et al. Ventriculomegaly associated with ependymal gliosis and declines in barrier integrity in the aging human and mouse brain. Aging Cell 2014;13:340-50.

19. Roales-Buján R, Páez P, Guerra M, et al. Astrocytes acquire morphological and functional characteristics of ependymal cells following disruption of ependyma in hydrocephalus. Acta Neuropathol 2012;124:531-46.

20. Gao C, Du H, Hua Y, et al. Role of red blood cell lysis and iron in hydrocephalus after intraventricular hemorrhage. J Cereb Blood Flow Metab 2014;34:1070-5.

21. Strahle JM, Garton T, Bazzi AA, et al. Role of hemoglobin and iron in hydrocephalus after neonatal intraventricular hemorrhage. Neurosurgery 2014;75:696-705; discussion 706.

22. Ip JP, Noçon AL, Hofer MJ, et al. Lipocalin 2 in the central nervous system host response to systemic lipopolysaccharide administration. $J$ Neuroinflammation 2011;8:124.

23. Richardson DR. $24 \mathrm{p} 3$ and its receptor: dawn of a new iron age? Cell 2005;123:1175-7.

24. Zhao J, Chen Z, Xi G, et al. Deferoxamine attenuates acute hydrocephalus after traumatic brain injury in rats. Trans/ Stroke Res 2014;5:586-94

25. Xing C, Wang $X$, Cheng $C$, et al. Neuronal production of lipocalin-2 as a help-me signal for glial activation. Stroke 2014;45:2085-92.

26. Jin M, Jang E, Suk K. Lipocalin-2 acts as a neuroinflammatogen in lipopolysaccharide-injected mice. Exp Neurobiol 2014;23:155-62. 